\title{
Mirtazapine for symptom control in refractory gastroparesis
}

\author{
This article was published in the following Dove Press journal: \\ Drug Design, Development and Therapy \\ 30 March 2017 \\ Number of times this article has been viewed
}

Introduction: Gastroparesis symptoms can be severe and debilitating. Many patients do not respond to currently available treatments. Mirtazapine has been shown in case reports to reduce symptoms in gastroparesis.

Aim: To assess the efficacy and safety of mirtazapine in gastroparetic patients.

Methods: Adults with gastroparesis and poorly controlled symptoms were eligible. Participants were prescribed mirtazapine $15 \mathrm{mg}$ PO qhs. Questionnaires containing the gastrointestinal cardinal symptom index (GCSI) and the clinical patient grading assessment scale (CPGAS) were completed by patients' pretreatment, at 2 weeks, and at 4 weeks. Primary end point was nausea and vomiting response to mirtazapine using the GCSI. Secondary end point was nausea and vomiting severity assessment using the CPGAS. $P$-values were calculated using the paired two-tailed Student's $t$-test. Intention to treat analysis was used.

Results: A total of 30 patients aged 19-86 years were enrolled. Of those, 24 patients (80\%) completed 4 weeks of therapy. There were statistically significant improvements in nausea, vomiting, retching, and perceived loss of appetite at 2 and 4 weeks (all $P$-values $<0.05$ ) compared with pretreatment. There was a statistically significant improvement in the CPGAS score at week $2(P=0.003)$ and week $4(P<0.001)$. Of the total patients, $14(46.7 \%)$ experienced adverse effects from mirtazapine and due to this, 6 patients stopped therapy.

Conclusion: Mirtazapine significantly improved both nausea and vomiting in gastroparetics after 2 and 4 weeks of treatment. Side effects led to treatment self-cessation in a fifth of patients. From these data, we conclude that mirtazapine improves nausea and vomiting, among other symptoms, in patients with gastroparesis and might be useful in select patients.

Keywords: gastroparesis, mirtazapine, nausea, vomiting

\section{Introduction}

Gastroparesis is a chronic disorder characterized by delayed gastric emptying in the absence of mechanical obstruction. The most common types of gastroparesis are diabetic, idiopathic, postsurgical, and postinfectious. ${ }^{1}$ Major symptoms of gastroparesis include nausea, early satiety, bloating, and vomiting. These symptoms can be debilitating, causing frequent hospitalizations and diminished quality of life. The current mainstays of medical therapy are primarily prokinetics (metoclopramide, domperidone, etc.) and antiemetics (ondansetron, promethazine, prochlorphenazine, and others). ${ }^{1,2}$ Nonmedical options include placement of gastric electrical stimulator. However, despite the multitude of therapeutic options available, many patients still have poor symptom control and new agents that may improve symptom control and quality of life in gastroparetics are still explored. One such agent is mirtazapine.

Mirtazapine (Remeron, Organon USA Inc., NJ, USA) is an antidepressant with a multifactorial mechanism of action involving antagonism of central and peripheral 
presynaptic alpha- 2 adrenergic receptors as well as actions on several subtypes of the 5-(hydroxytryptamine) HT serotonin receptors and the $\mathrm{H} 1$ histamine receptor. ${ }^{3}$ Of particular interest in relation to gastroparesis, symptom control is mirtazapine's agonism of central and peripheral 5-HT1A serotonin receptors. This receptor is known to contribute to gastric receptive fundic relaxation, and its stimulation by mirtazapine has been shown in multiple double-blinded, randomized, placebo-controlled trials to improve symptom control, weight loss, early satiation, and overall quality of life in patients with functional dyspepsia. ${ }^{4-7}$ It has been recognized as an effective antiemetic in several settings: palliative care, chemotherapy patients, postsurgery patients, and even idiopathic nausea and vomiting. ${ }^{8-13}$ Most notably, Tack et al have found in multiple randomized placebo-controlled trials that mirtazapine is effective for nausea and other symptoms in functional dyspepsia, a condition with similar symptomatology to gastroparesis. ${ }^{5,7}$ However, there are only a handful of case reports on the effect of mirtazapine in gastroparesis. Studies in canines have shown that mirtazapine can accelerate gastric emptying, and four human case reports have shown rapid and dramatic improvement in or resolution of symptoms in gastroparetic patients previously refractory to extensive medical regimens. ${ }^{14-18}$

To date, there have been no large-scale studies evaluating the efficacy of mirtazapine for symptom control in gastroparesis. Our goal in this study was to assess efficacy and safety of mirtazapine in patients with gastroparesis.

\section{Methods}

Patients seen in our tertiary care hospital-associated outpatient clinic were diagnosed with gastroparesis, and initiating mirtazapine for clinical treatment was offered participation in the study. Inclusion criteria included age $>18$ years, scintigraphy-proven delayed gastric emptying (defined as nuclear medicine gastric emptying study [GES] 4-hour residue $>10 \%$ ), esophagogastroduodenoscopy negative for obstruction, and subjectively determined poor symptom control despite initial treatments. Patients were excluded if they refused to participate in the registry protocol. The study was approved by the Temple University Institutional Review Board. All patients had a basic metabolic panel without significant abnormality prior to mirtazapine initiation and were not on any antiemetics or narcotics for at least 8 weeks before the enrollment.

After signing an informed consent for study participation, the patients were prescribed mirtazapine $15 \mathrm{mg}$ daily taken at bedtime. Prior to treatment initiation, patients filled out questionnaires containing the gastroparesis cardinal symptom index (GCSI) and the clinical patient grading assessment scale (CPGAS). Patients filled out these same questionnaires after 2 weeks of treatment and after 4 weeks of treatment.

The GCSI is a validated patient-centric tool for assessing symptom severity in gastroparesis. ${ }^{19}$ For each of several gastrointestinal symptoms, patients were assigned a score ranging from 0 (none) to 5 (very severe) to describe their experience of that symptom over a given period or point in time. A lower GCSI score represents better symptom control. The CPGAS is another patient-centric tool that allows patients to quantify changes in symptom control over a given period of time with scores ranging from -7 (a very great deal worse) through 0 (about the same) to +7 (a very great deal better). We used intention to treat analysis and patients who stopped therapy after 2 weeks were included. They were assigned the same week 4 GCSI score as week 2 and a week 4 CPGAS score of 0 , signifying no change from weeks 2 to 4 .

Our primary end point was nausea and vomiting response to mirtazapine according to the GCSI score. Our secondary end point was nausea and vomiting severity assessment using the CPGAS score. Mean GCSI scores, GCSI score changes, and CGPAS scores with standard deviation were calculated for pretreatment, 2 weeks of therapy, and 4 weeks of therapy. $P$-values were calculated using the paired twotailed Student's $t$-test or chi-square test.

\section{Results \\ Demographics}

A total of 30 patients (F-25; mean age $46 \pm 20$ years; mean body mass index [BMI] 25.1 \pm 5.8 ) were enrolled in our study. The majority of them had idiopathic gastroparesis $(24 / 30$, $80 \%$ ), whereas $4 / 30(13.3 \%)$ had diabetic gastroparesis, $1 / 30(3.3 \%)$ had postsurgical gastroparesis, and 1/30 (3.3\%) had post-viral gastroparesis. The average 4-hour residue on nuclear medicine GES was $28.5 \%( \pm 12.6)$. Complete patient demographics can be seen in Table 1. Of total, $24(80 \%)$ patients completed all 4 weeks of therapy, whereas $6(20 \%)$ patients stopped after 2 weeks due to adverse effects.

\section{Outcomes}

We noted a statistically significant improvement in the nausea and vomiting GCSI score at 2 weeks ( $P<0.001$ for both) and at 4 weeks $(P<0.001$ for both) compared with pretreatment (Table 2; Figure 1). Among the other GCSI variables, we noted a statistically significant improvement in perceived loss of appetite at both 2 and 4 weeks $(P=0.045$ and $P=0.02$, respectively), in retching at both 2 and 4 weeks ( $P=0.02$ for both), 
Table I Patient characteristics

\begin{tabular}{ll}
\hline Variables & Value \\
\hline Total number of patients & 30 \\
Average age (years) & $46(\mathrm{SD} \pm 20)$ \\
Female sex & $25(83)$ \\
BMI $\left(\mathrm{kg} / \mathrm{m}^{2}\right)$ & $25 . \mathrm{I}(\mathrm{SD} \pm 5.8)$ \\
Ethnicity & \\
$\quad$ Caucasian & $24(80)$ \\
$\quad$ African American & $3(\mathrm{I} 0)$ \\
Latino & $3(\mathrm{I} 0)$ \\
Average GES 4-hour residue & $28.5(\mathrm{SD} \pm \mathrm{I} 2.6)$ \\
Diabetes (type I or II) & $4(\mathrm{I} .3)$ \\
CCY & $5(\mathrm{I} 6.7)$ \\
Abdominal surgery (other than CCY) & $\mathrm{I}(3.3)^{\mathrm{a}}$ \\
Current no. of gastroparesis medications & $1.2(\mathrm{SD} \pm 0.9)$ \\
No. of gastroparesis medications tried previously & $3(\mathrm{SD} \pm \mathrm{I} .0)$ \\
Prior intrapyloric botulinum toxin injection & $9(3.0)$ \\
Current enterra gastric electric stimulator & $2(6.7)$ \\
Main symptom, \% & \\
Nausea & $19(63.3)$ \\
Vomiting & $5(\mathrm{I} .7)$ \\
Abdominal pain & $4(\mathrm{I} .3 .3)$ \\
Bloating & $2(6.7)$ \\
\hline Notes &
\end{tabular}

Notes: a This patient underwent Whipple procedure. Data presented as n (\%) unless otherwise stated.

Abbreviations: BMI, body mass index; $\mathrm{CCY}$, cholecystectomy; GES, gastric emptying study; SD, standard deviation.

and in perceived ability to finish a "normal-sized meal" at 4 weeks $(P=0.03)$ compared with pretreatment. Nausea and vomiting, as assessed by the CPGAS, significantly improved at both 2 weeks $(P=0.003)$ and 4 weeks $(P<0.001)$ compared with pretreatment.

\section{Predictors of response}

For all GCSI variables with significant 2 and 4 weeks changes (nausea, vomiting, retching, and loss of appetite), demographics among responders and nonresponders were assessed to evaluate for any predictors of response. Responders were defined as patients with a negative GCSI score change (signifying a lower score, and thus an improvement in symptom control) at week 2 and/or week 4. Patients with no change or a positive GCSI score change were considered nonresponders. Variables assessed included age, BMI, ethnicity, gastroparesis etiology, and GES 4-hour residue. Etiology was characterized as idiopathic or non-idiopathic.

Patients with idiopathic gastroparesis tended to have improvements in vomiting more than those with non-idiopathic gastroparesis $(P=0.05)$. In addition, older age predicted increased improvement in the loss of appetite $(P=0.02)$. Otherwise, there were no statistically significant differences in any of these variables between responders and nonresponders (Table 3 for nausea, Table 4 for vomiting, Table 5 for retching, and Table 6 for the loss of appetite).

\section{Side effects}

Several patients reported adverse side effects after starting mirtazapine. In total, 14/30 patients (46.7\%) experienced at least one side effect. Eight of these 14 patients (57\%) experienced more than one adverse effect. The most commonly reported adverse effects were drowsiness and lethargy/ fatigue. Other uncommon side effects included constipation, disoriented thinking, increased appetite, weight gain, depression, mood swings, and slurred speech (Table 7). A total of six patients stopped treatment prior to 4 weeks. Adverse side effects resolved spontaneously during treatment in two patients. Of note, the same patient accounted for the single occurrence of depression, mood swings, and slurred speech.

Table 2 GCSI and CPGAS scores pretreatment, at 2 weeks, and at 4 weeks with average score changes

\begin{tabular}{|c|c|c|c|c|c|}
\hline GCSI category & $\begin{array}{l}\text { Mean pre-treatment } \\
\text { score } \pm \text { SD }\end{array}$ & $\begin{array}{l}\text { Mean } 2 \text { week } \\
\text { score } \pm \text { SD }(P \text {-value })\end{array}$ & $\begin{array}{l}\text { Mean } 2 \text { week } \\
\text { change } \pm \text { SD }\end{array}$ & $\begin{array}{l}\text { Mean } 4 \text { week } \\
\text { score } \pm S D \text { ( } P \text {-value })\end{array}$ & $\begin{array}{l}\text { Mean } 4 \text { week } \\
\text { change } \pm \text { SD }\end{array}$ \\
\hline Nausea & $4.0 \pm 1.3$ & $2.9 \pm I . I(<0.00 I)$ & $-I . I \pm I .4$ & $2.76 \pm 1.6(<0.001)$ & $-1.16 \pm 1.5$ \\
\hline Retching & $2.6 \pm 1.9$ & $1.9 \pm 1.9(0.02)$ & $-0.68 \pm 15$ & $1.8 \pm 18(0.02)$ & $-0.86 \pm I .7$ \\
\hline Vomiting & $2 I \pm I .8$ & $1.4 \pm 1.9(<0.001)$ & $-0.6 \pm 0.6$ & $1.2 \pm 1.8(<0.00 I)$ & $-0.8 \pm 0.9$ \\
\hline Stomach fullness & $3.2 \pm 1.4$ & $2.8 \pm 1.8(0.16)$ & $-0.4 \pm 1.35$ & $3.0 \pm 1.6(0.23)$ & $-0.3 \pm 1.1$ \\
\hline Loss of appetite & $2.8 \pm 1.5$ & $2.2 \pm 2.0(0.045)$ & $-0.56 \pm I .4$ & $2.0 \pm 1.8(0.02)$ & $-0.8 \pm I .4$ \\
\hline Not able to finish a normal-sized meal & $2.9 \pm 1.5$ & $2.6 \pm 1.6(0.15)$ & $-0.3 \pm 1.1$ & $2.3 \pm 1.6(0.03)$ & $-0.6 \pm 1.4$ \\
\hline Feeling excessively full after meals & $3.0 \pm 1.8$ & $2.7 \pm 2.1(0.46)$ & $-0.2 \pm 1.6$ & $3.0 \pm 2.0(037)$ & $-0.3 \pm 1.5$ \\
\hline Stomach or belly visibly larger & $2.8 \pm 1.9$ & $2.5 \pm 1.8(0.45)$ & $-0.3 \pm 1.8$ & $2.4 \pm 1.7(0.33)$ & $-0.52 \pm 2.0$ \\
\hline Bloating & $2.7 \pm 1.8$ & $3 \pm 2.0(0.76)$ & $-0.1 \pm 1.3$ & $2.3 \pm 1.6(0.29)$ & $-0.4 \pm 1.9$ \\
\hline Upper abdominal discomfort & $2.6 \pm 1.5$ & $2.5 \pm 1.6(0.85)$ & $0.0 \pm 1.02$ & $2.5 \pm 1.6(0.86)$ & $0.0 \pm \mathrm{I} . \mathrm{I}$ \\
\hline Upper abdominal pain & $2.6 \pm 1.6$ & $2.2 \pm 1.9(0.12)$ & $-0.44 \pm 1.3$ & $2.2 \pm 1.9(0.06)$ & $-0.44 \pm 1.1$ \\
\hline CPGAS score & 0 & $1.72 \pm 2.7(0.003)$ & $1.72 \pm 2.7$ & $2.2 \pm 2.7(<0.001)$ & $2.2 \pm 2.7$ \\
\hline
\end{tabular}

Notes: Categories with statistically significant findings (nausea, vomiting, loss of appetite, retching, week 4 "not able to finish normal-size meal", and CPGAS score) are in bold. Note that the last two symptom categories, diarrhea and constipation, were omitted for this study.

Abbreviations: CPGAS, clinical patient grading assessment scale; GCSI, gastroparesis cardinal symptom index; SD, standard deviation. 


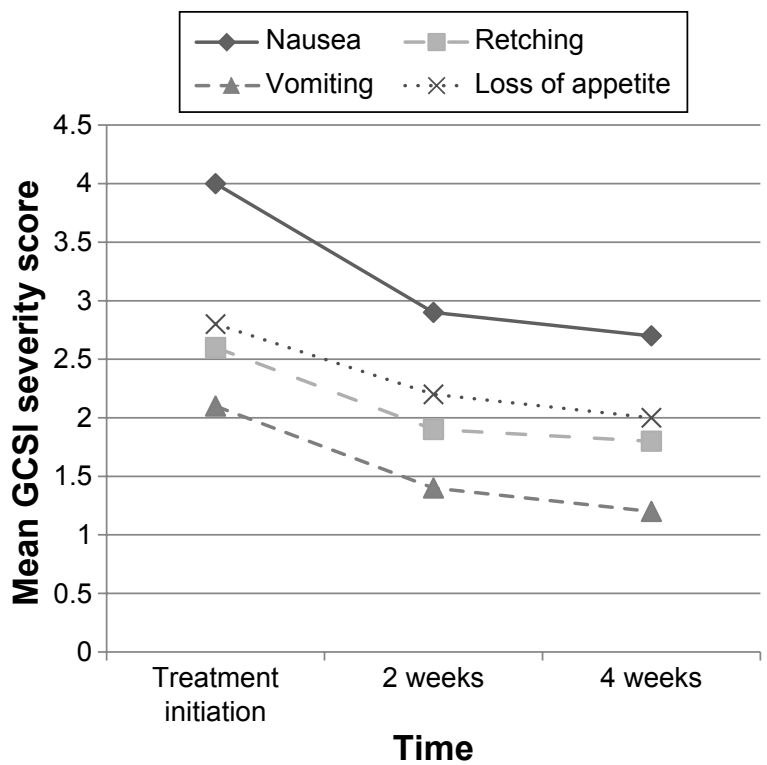

Figure I Mean GCSI severity scores at treatment initiation, 2 weeks, and 4 weeks after treatment with mirtazapine.

Note: The four variables with statistically significant 2 and 4 weeks changes (nausea, vomiting, retching, and loss of appetite) were included.

Abbreviation: GCSI, gastroparesis cardinal symptom index.

\section{Discussion}

Despite a multitude of pharmacologic treatment modalities (albeit all off-label with the exception metoclopramide) and growing interest in interventional/surgical techniques, ${ }^{1,2}$ many patients with gastroparesis have poor symptom control. Among the symptoms, these patients experience, nausea and vomiting are the most prevalent. Thus, there is much interest in finding new agents to help alleviate these potentially debilitating symptoms.

Our study is the first prospective multipatient examination of the effectiveness and potential side effects of mirtazapine

Table 3 Demographics of nausea responders vs nonresponders

\begin{tabular}{llll}
\hline Variables & $\begin{array}{l}\text { Responders } \\
(\mathbf{n}=\mathbf{2 4})\end{array}$ & $\begin{array}{l}\text { Nonresponders } \\
(\mathbf{n}=\mathbf{6})\end{array}$ & P-value \\
\hline Age (years), mean \pm SD & $47.8 \pm 18.7$ & $37.2 \pm 22.5$ & 0.12 \\
BMI $\left(\mathrm{kg} / \mathrm{m}^{2}\right)$, mean \pm SD & $24.6 \pm 5.3$ & $27.3 \pm 7.5$ & 0.31 \\
GES 4-hour residue (\%), & $27.8 \pm 13.5$ & $31.5 \pm 8.9$ & 0.53 \\
$\begin{array}{l}\text { mean } \pm \text { SD } \\
\text { Ethnicity }\end{array}$ & & \\
$\begin{array}{l}\text { Caucasian } \\
\text { Non-Caucasian }\end{array}$ & 19 & 5 & $0.82^{\mathrm{a}}$ \\
Etiology & 5 & $\mathrm{I}$ & \\
$\begin{array}{l}\text { Idiopathic } \\
\text { Non-idiopathic }\end{array}$ & 18 & 6 & $0.17^{\mathrm{b}}$ \\
\hline
\end{tabular}

Notes: For GES, $\leq 10 \%$ residue after 4 hours is considered normal while $>10 \%$ is consistent with gastroparesis. ${ }^{a}$ Represents comparison of Caucasian vs nonCaucasian participants; 'bepresents comparison of idiopathic vs non-idiopathic gastroparesis; 'includes diabetic (4), postsurgical (I), and post-viral (I).

Abbreviations: BMI, body mass index; GES, gastric emptying study; SD, standard deviation.
Table 4 Demographics of vomiting responders vs nonresponders

\begin{tabular}{|c|c|c|c|}
\hline Variables & $\begin{array}{l}\text { Responders } \\
(n=20)\end{array}$ & $\begin{array}{l}\text { Nonresponders } \\
(\mathrm{n}=10)\end{array}$ & $P$-value \\
\hline Age (years), mean $\pm S D$ & $45.2 \pm 17.1$ & $46.7 \pm 24.8$ & 0.93 \\
\hline BMI $\left(\mathrm{kg} / \mathrm{m}^{2}\right)$, mean $\pm \mathrm{SD}$ & $24.6 \pm 5.7$ & $26.1 \pm 6.2$ & 0.52 \\
\hline $\begin{array}{l}\text { GES 4-hour residue (\%), } \\
\text { mean } \pm \text { SD }\end{array}$ & $30.9 \pm 12.9$ & $23.9 \pm 11.4$ & 0.18 \\
\hline Ethnicity & & & $1.0^{\mathrm{a}}$ \\
\hline Caucasian & 16 & 8 & \\
\hline Non-Caucasian & 4 & 2 & \\
\hline Etiology & & & $0.052^{\mathrm{b}}$ \\
\hline Idiopathic & 14 & 10 & \\
\hline Non-idiopathic ${ }^{c}$ & 6 & 0 & \\
\hline
\end{tabular}

Notes: For GES, $\leq 10 \%$ residue after 4 hours is considered normal while $>10 \%$ is consistent with gastroparesis. ${ }^{2}$ Represents comparison of Caucasian vs nonCaucasian participants; 'bepresents comparison of idiopathic vs non-idiopathic gastroparesis; includes diabetic (4), postsurgical (I), and post-viral (I).

Abbreviations: BMI, body mass index; GES, gastric emptying study; SD, standard deviation.

when used for the treatment of refractory nausea and vomiting in patients with gastroparesis. We found that mirtazapine led to a significant improvement in both nausea and vomiting at 2 and 4 weeks of therapy compared to baseline in gastroparetics. We also noted significant improvements in CPGAS scores at both 2 and 4 weeks compared to baseline. However, although there was a trend of improvement between weeks 2 and 4 , this did not reach statistical significance. In addition to our primary and secondary end points, we found significant improvements in perceived loss of appetite and retching at 2 and 4 weeks, and in perceived ability to finish a "normal-sized meal" at 4 weeks of treatment with mirtazapine (Table 2; Figure 1).

\section{Interpretation of results}

The results of our study suggest that mirtazapine can be a useful tool in treating nausea and vomiting caused by gastroparesis,

Table 5 Demographics for retching responders vs nonresponders

\begin{tabular}{|c|c|c|c|}
\hline Variables & $\begin{array}{l}\text { Responders } \\
(n=17)\end{array}$ & $\begin{array}{l}\text { Nonresponders } \\
(n=13)\end{array}$ & $P$-value \\
\hline Age (years), mean $\pm S D$ & $43.2 \pm 18.2$ & $48.8 \pm 21.5$ & 0.44 \\
\hline BMI $\left(\mathrm{kg} / \mathrm{m}^{2}\right)$, mean $\pm \mathrm{SD}$ & $25.4 \pm 6.0$ & $24.8 \pm 5.7$ & 0.79 \\
\hline $\begin{array}{l}\text { GES 4-hour residue (\%), } \\
\text { mean } \pm \text { SD }\end{array}$ & $31.8 \pm 13.8$ & $24.2 \pm 9.8$ & 0.10 \\
\hline Ethnicity & & & $0.58^{\mathrm{a}}$ \\
\hline Caucasian & 13 & II & \\
\hline Non-Caucasian & 4 & 2 & \\
\hline Etiology & & & $0.14^{\mathrm{b}}$ \\
\hline Idiopathic & 12 & 12 & \\
\hline Non-idiopathic ${ }^{c}$ & 5 & I & \\
\hline
\end{tabular}

Notes: For GES, $\leq 10 \%$ residue after 4 hours is considered normal while $>10 \%$ is consistent with gastroparesis. ${ }^{2}$ Represents comparison of Caucasian vs non-Caucasian participants; 'bepresents comparison of idiopathic vs non-idiopathic gastroparesis; cincludes diabetic (4), postsurgical (I), and post-viral (I).

Abbreviations: BMI, body mass index; GES, gastric emptying study; SD, standard deviation. 
Table 6 Demographics for perceived loss of appetite responders vs nonresponders

\begin{tabular}{llll}
\hline Variables & $\begin{array}{l}\text { Responders, } \\
\mathbf{n}=\mathbf{1 9}\end{array}$ & $\begin{array}{l}\text { Nonresponders, } \\
\mathbf{n}=\mathbf{I ~ I ~}\end{array}$ & $\mathbf{P}$-value \\
\hline Age (years), mean \pm SD & $51.7 \pm 18.8$ & $35.3 \pm 16.9$ & 0.02 \\
BMI (kg/m²), mean \pm SD & $24.6 \pm 5.4$ & $26 \pm 6.6$ & 0.54 \\
$\begin{array}{l}\text { GES 4-hour residue (\%), } \\
\text { mean } \pm \text { SD }\end{array}$ & $27 \pm 13$ & $31.2 \pm 11.2$ & 0.39 \\
Ethnicity & & & \\
Caucasian & 15 & 9 & $0.85^{\mathrm{a}}$ \\
Non-Caucasian & 4 & 2 & \\
Etiology & & & $0.87^{\mathrm{b}}$ \\
$\begin{array}{l}\text { Idiopathic } \\
\text { Non-idiopathic }\end{array}$ & 16 & 9 & \\
\hline
\end{tabular}

Notes: For GES, $\leq 10 \%$ residue after 4 hours is considered normal while $>10 \%$ is consistent with gastroparesis. ${ }^{a}$ Represents comparison of Caucasian vs nonCaucasian participants; 'bepresents comparison of idiopathic vs non-idiopathic gastroparesis; 'includes diabetic (4), postsurgical (I), and post-viral (I).

Abbreviations: BMI, body mass index; GES, gastric emptying study; SD, standard deviation.

among other symptoms. When asked to characterize the changes in their nausea and vomiting after starting mirtazapine both quantitatively (GCSI score) and qualitatively (CPGAS score), our patients felt better. Only a small number of patients did not experience at least a minimal improvement in their nausea $(6 / 20,24 \%)$ or vomiting $(10 / 30,33.3 \%)$. There was only a single patient $(1 / 30,3.33 \%)$ who noted a worsening in nausea while no patients noted a worsening in vomiting.

When we analyzed demographic variables among responders and nonresponders, we noted one statistically significant correlation: those who had improvement in perceived loss of appetite tended to be older. Other patterns trended toward statistical significance, but did not meet it. The most notable example is the relationship of gastroparesis etiology and improvement in vomiting. Patients with idiopathic gastroparesis significantly improved more than those with non-idiopathic gastroparesis. When the age of responders was compared with the age of nonresponders for nausea, a fairly large difference in the mean age was found (49.2 vs 37.2 years). However, there were only 6 nonresponders compared with 24 responders, and thus the $P$-value was insignificant at 0.12 . This may represent a type II error that would correct itself with a larger sample size. As Tables 3-6 show, there were several other variables with noticeable differences between responders and nonresponders, but $P$-values were falling well short of significance.

Although the adverse side effects were experienced in about half of our patients, only six patients actually stopped taking their mirtazapine because of them. This suggests that the major adverse side effects caused by mirtazapine are outweighed by its beneficial effects on nausea and vomiting.

\section{Study limitations}

Our study is not without limitations. First, the study was not blinded or placebo controlled. A placebo-controlled study would have added another layer of validity to the findings and such a study is in its preliminary phases. However, this cohort of patients had "tried it all" with a partial or null response; hence, it would be unlikely for them to be substantially influenced by placebo effect, and it is our belief that the effect of the drug is real in most or all of the cases. Nevertheless, we do acknowledge the potential placebo-controlled pitfall of this study. Operator blinding may not have been as necessary in this case given that all results were derived from patient answered surveys, and thus there was no opportunity for researcher bias to affect the results. In addition, the demographics of our study in terms of gastroparesis etiology do not closely resemble that of a general gastroparetic population. It is believed that the three most common etiologies of gastroparesis are idiopathic (36\%), diabetic (29\%), and postsurgical (13\%). ${ }^{1,20,21}$ Our cohort overwhelmingly had a high percentage of idiopathic gastroparesis $(24 / 30,80 \%)$ while only $4(13.3 \%)$ had diabetic, $1(3.3 \%)$ postsurgical,

Table 7 Side-effect profile experienced by patients taking mirtazapine for gastroparesis

\begin{tabular}{|c|c|c|c|}
\hline Symptom & $\begin{array}{l}\text { Total no. of patients } \\
\text { experiencing symptom }\end{array}$ & $\begin{array}{l}\text { No. of patients who } \\
\text { stopped at } 2 \text { weeks }\end{array}$ & $\begin{array}{l}\text { No. of patients who } \\
\text { completed } 4 \text { weeks }\end{array}$ \\
\hline Drowsiness & 4 & 2 & 2 \\
\hline Fatigue/lethargy & 7 & 4 & 3 \\
\hline Constipation & I & 0 & I \\
\hline Weight gain & 2 & I & I \\
\hline Slurred speech ${ }^{\mathrm{a}}$ & I & I & 0 \\
\hline Mood swings ${ }^{\mathrm{a}}$ & 1 & 1 & 0 \\
\hline Depression $^{\mathrm{a}}$ & 1 & 1 & 0 \\
\hline Increased appetite & I & 0 & I \\
\hline Disoriented thinking & I & I & 0 \\
\hline
\end{tabular}

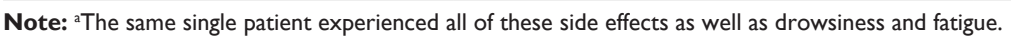


and $1(3.3 \%)$ post-viral. Unfortunately, due to our sample size, we could not conduct a meaningful subgroup analyses. Ideally, though, we would have had a study population that more closely resembled the general gastroparesis one.

Finally, we did not take psychiatric disease into account when enrolling patients and calculating data. Mirtazapine is an antidepressant and given the incompletely understood relationship between gastrointestinal and psychosomatic function, it is possible that some portion of the effects it had were more related to the improvement of mood. A comparison of results in patients with and without a psychiatric diagnosis, along with administration of the patient health questionnaire-9 and generalized anxiety disorder-7 questionnaire before and after treatment, may have helped clarify this. However, the degree of symptom improvement that was psychosomatically driven may not actually matter for our purposes. The main aim of our study was to assess for symptom improvement through the use of mirtazapine, which we did. We believe that the mechanism of this improvement may be psychosomatic and/or physiologic.

In conclusion, our study showed that in patients with gastroparesis and symptoms refractory to prior treatment, mirtazapine significantly improves both nausea and vomiting after 2 and 4 weeks of treatment. It also improves appetite, increases ability to finish a perceived normal-sized meal, and decreases retching. Mirtazapine does cause adverse side effects but in the majority of patients who experience them they are mild and do not lead to medication discontinuation. Thus, mirtazapine is a useful agent for decreasing nausea and vomiting in patients with gastroparesis. Other common symptoms such as retching, loss of appetite, and inability to finish a normal-sized meal are improved by mirtazapine as well. A larger placebo-controlled trial is the next step in verifying this indication for mirtazapine and determining reliable predictors of response.

\section{Author contributions}

All authors contributed toward data analysis, drafting and revising the paper and agree to be accountable for all aspects of the work.

\section{Disclosure}

The authors report no conflicts of interest in this work.

\section{References}

1. Camilleri M, Parkman HP, Shafi MA, Abell TL, Gerson L; American College of Gastroenterology. Clinical guideline: management of gastroparesis. Am J Gastroenterol. 2013;108(1):18-38.
2. Malamood M, Parkman H, Schey R. Current advances in treatment of gastroparesis. Expert Opin Pharmacother. 2015;16(13):1997-2008.

3. FDA Mirtazapine Summary. Available from: http://www.fda.gov/ ohrms/dockets/ac/04/briefing/2004-4065b1-26-tab11G-Remeron-TabsSLR016.pdf. Accessed June 3, 2016.

4. Van Oudenhove L, Kindt S, Vos R, Coulie B, Tack J. Influence of buspirone on gastric sensorimotor function in man. Aliment Pharmacol Ther. 2008;28(11-12):1326-1333.

5. Tack J, Janssen P, Masaoka T, Farré R, Van Oudenhove L. Efficacy of buspirone, a fundus-relaxing drug, in patients with functional dyspepsia. Clin Gastroenterol Hepatol. 2012;10(11):1239-1245.

6. Van Oudenhove L, Holvoet L, Bisschops R, et al. A double-blind, randomized, placebo-controlled study of mirtazapine in functional dyspepsia with weight loss. Gastroenterology. 2009;136(5):A46.

7. Tack J, Ly HG, Carbone F, et al. Efficacy of mirtazapine in patients with functional dyspepsia and weight loss. Clin Gastroenterol Hepatol. 2016;14(3):385-392.e4.

8. Kast RE, Foley KF. Cancer chemotherapy and cachexia: mirtazapine and olanzapine are 5-HT3 antagonists with good antinausea effects. Eur J Cancer Care (Engl). 2007;16(4):351-354.

9. Teixeira FV, Novaretti TM, Pilon B, Pereira PG, Breda MF. Mirtazapine (Remeron) as treatment for non-mechanical vomiting after gastric bypass. Obes Surg. 2005;15(5):707-709.

10. Shibahara H, Ito T, Uematsu N, Imai E, Nishimura D. Low-dose mirtazapine improved nausea and appetite loss during S-1 therapy. Gan To Kagaku Ryoho. 2012;39(1):143-145. Japanese.

11. Shibahara H, Uematsu N, Imai E, Tokura Y, Nishimura D. Effectiveness of miratazapine for digestive symptoms in palliative care - a retrospective study of 50 cases. Gan To Kagaku Ryoho. 2014;41(3):329-333. Japanese.

12. Pae CU. Low-dose mirtazapine may be successful treatment option for severe nausea and vomiting. Prog Neuropsychopharmacol Biol Psychiatry. 2006;30(6):1143-1145.

13. Huerta S, Siddigui A. Intractable nausea and vomiting following Roux-en-Y gastric bypass: role of mirtazapine. Obes Surg. 2006;16(10):1399.

14. Yin J, Song J, Lei Y, Xu X, Chen JD. Prokinetic effects of mirtazapine on gastrointestinal transit. Am J Physiol Gastrointest Liver Physiol. 2014; 306(9):G796-G801.

15. Kundu S, Rogal S, Alam A, Levinthal DJ. Rapid improvement in post-infectious gastroparesis symptoms with mirtazapine. World $J$ Gastroenterol. 2014;20(21):6671-6674.

16. Gooden JY, Takahashi PY. Mirtazapine treatment of diabetic gastroparesis as a novel method to reduce tube-feed residual: a case report. J Med Case Rep. 2013;7:38.

17. Johnstone M, Buddhdev P, Peter M, Diggory R. Mirtazapine: a solution for post-operative gastroparesis? BMJ Case Rep. 2009;2009. pii: bcr02.2009.1579.

18. Kim SW, Shin IS, Kim JM, et al. Mirtazapine for severe gastroparesis unresponsive to conventional prokinetic treatment. Psychosomatics. 2006;47(5):440-442.

19. Revicki DA, Rentz AM, Dubois D, et al. Development and validation of a patient-assessed gastroparesis symptom severity measure: the gastroparesis cardinal symptom index. Aliment Pharmacol Ther. 2003; 18(1):141-150.

20. Parkman HP, Yates K, Hasler WL, et al; National Institute of Diabetes and Digestive and Kidney Diseases Gastroparesis Clinical Research Consortium. Similarities and differences between diabetic and idiopathic gastroparesis. Clin Gastroenterol Hepatol. 2011;9(12):1056-1064.

21. Parkman HP, Yates K, Hasler WL, et al; National Institute of Diabetes and Digestive and Kidney Diseases Gastroparesis Clinical Research Consortium. Clinical features of idiopathic gastroparesis vary with sex, body mass, symptom onset, delay in gastric emptying, and gastroparesis severity. Gastroenterology. 2011;140(1):101-115. 


\section{Publish your work in this journal}

Drug Design, Development and Therapy is an international, peerreviewed open-access journal that spans the spectrum of drug design and development through to clinical applications. Clinical outcomes, patient safety, and programs for the development and effective, safe, and sustained use of medicines are the features of the journal, which has also been accepted for indexing on PubMed Central. The manuscript management system is completely online and includes a very quick and fair peer-review system, which is all easy to use. Visit http://www.dovepress.com/testimonials.php to read real quotes from published authors.

Submit your manuscript here: http://www.dovepress.com/drug-design-development-and-therapy-journal 